\title{
Characteristics of Adults with Migraine in Alberta, Canada: A Population-Based Study
}

\author{
Lawrence Richer, Kai On Wong, Karen J.B. Martins (D), Thilinie Rajapakse, \\ Farnaz Amoozegar, Werner J. Becker, Scott W. Klarenbach
}

\begin{abstract}
Background: Migraine, including episodic migraine (EM) and chronic migraine (CM), is a common neurological disorder that imparts a substantial health burden. Objective: Understand the characteristics and treatment of EM and CM from a population-based perspective. Methods: This retrospective population-based cross-sectional study utilized administrative data from Alberta. Among those with a migraine diagnostic code, CM and EM were identified by an algorithm and through exclusion, respectively; characteristics and migraine medication use were examined with descriptive statistics. Results: From 79,076 adults with a migraine diagnostic code, 12,700 met the criteria for $\mathrm{CM}$ and 54,686 were considered to have EM. The majority of migraineurs were female, the most common comorbidity was depression, and individuals with $\mathrm{CM}$ had more comorbidities than EM. A larger proportion of individuals with $\mathrm{CM}$ versus $\mathrm{EM}$ were dispensed acute $(80.6 \%$ : $\mathrm{CM}$; 63.4\%: $\mathrm{EM})$ and preventative (58.0\%: $\mathrm{CM} ; 28.9 \%$ : EM) migraine medications over 1 year. Among those with a dispensation, individuals with $\mathrm{CM}$ had more acute (13.6 \pm 32.2 vs. $4.6 \pm 10.9$ [mean \pm standard deviation], $95 \%$ confidence interval [CI] 7.7-8.3), and preventative (12.6 \pm 43.5 vs. $5.0 \pm 12.6,95 \%$ CI $6.9-8.4)$ migraine medication dispensations than EM, over 1-year. Opioids were commonly used in both groups (proportion of individuals dispensed an opioid over 1year: 53.1\%: CM; 25.7\%: EM). Conclusions: Individuals with EM and CM displayed characteristics and medication use patterns consistent with other reports. Application of this algorithm for CM may be a useful and efficient means of identifying subgroups of migraine using routinely collected health data in Canada.
\end{abstract}

RÉSUMÉ : Caractéristiques des adultes souffrant de migraines en Alberta (Canada) : une étude basée sur la population. Contexte : Les migraines, notamment les migraines épisodiques (ME) et les migraines chroniques (MC), constituent des troubles neurologiques courants qui peuvent représenter un fardeau considérable en matière de santé. Objectif : Comprendre les caractéristiques et les traitements des ME et des MC dans une perspective populationnelle. Méthodes : Cette étude transversale populationnelle de nature rétrospective a fait appel à des données administratives de l'Alberta. Parmi tous les patients ayant donné à voir un code diagnostic de migraine, les patients souffrant de MC ou de ME ont été identifiés respectivement par un algorithme et par exclusion. Les caractéristiques de ces patients, de même que leur consommation de médicaments contre la migraine, ont été analysées au moyen de statistiques descriptives. Résultats : Sur un total de 79076 adultes à qui l'on avait assigné un code diagnostic de migraine, 12700 ont satisfait aux critères des MC tandis que 54686 ont été inclus dans le groupe de patients souffrant de ME. La majorité de ces patients était de sexe féminin. La comorbidité la plus fréquente s'est révélée être la dépression. À noter que les individus souffrant de MC avaient davantage de comorbidités que ceux souffrant de ME. Qui plus est, une plus grande proportion d'individus souffrant de MC ont bénéficié d'un traitement énergique contre la migraine $(80,6 \%$ contre $63,4 \%$ pour ceux souffrant de ME) ainsi que d'un traitement de nature préventive $(58,0 \%$ contre $28,9 \%$ pour ceux souffrant de ME) au cours d'une période d'un an. Parmi les patients bénéficiant de tels traitements, ceux souffrant de MC ont davantage bénéficié d'un traitement énergique $(13,6 \pm 32,2$ contre 4,6 $\pm 10,9$ [moyenne \pm écart type] ; IC $95 \%$ 7,7 - 8,3) et d'un traitement préventif (12,6 $\pm 43,5$ contre $5,0 \pm 12,6$; IC $95 \% 6,9-8,4)$ au cours d'une période d'un an. Mentionnons enfin que des opioïdes ont été communément utilisés dans chacun de ces groupes et que la proportion d'individus qui en ont reçus pendant un an a varié de 53,1\% (MC) à 25,7 \% (ME). Conclusions : Les individus souffrant de ME et de MC ont donné à voir des caractéristiques et des habitudes de consommation de médicaments qui rejoignent celles signalées dans d'autres études. L'application de cet algorithme pour les cas de MC pourrait s'avérer une façon utile et efficace d'identifier des sous-groupes de patients souffrant de migraine, et ce, en utilisant des données de santé collectées de manière routinière au Canada.

Keywords: Chronic migraine, Episodic migraine, Demographics, Comorbidity, Medication use, Retrospective study doi:10.1017/cjn.2021.68

Can J Neurol Sci. 2022; 49: 239-248

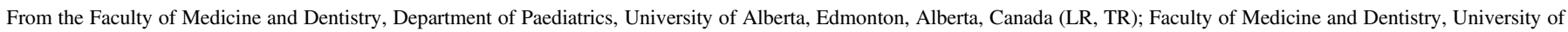

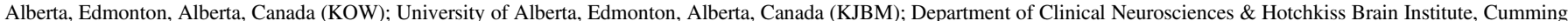

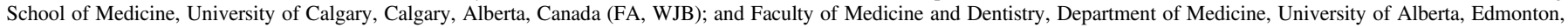
Alberta, Canada (SWK)

Received December 23, 2020. Final Revisions Submitted March 19, 2021. Date of Acceptance April 1, 2021.

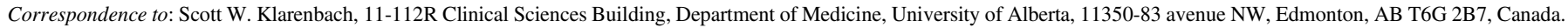
Email: swk@ualberta.ca 


\section{INTRODUCTION}

Migraine is a common neurological disorder characterized by recurrent headaches that are moderate-to-severe in nature and lead to significant symptoms and disability. Migraine can be subdivided into episodic and chronic; episodic migraine (EM) is defined as having $<15$ headache days per month, and chronic migraine $(\mathrm{CM})$ is defined as a headache occurring on $\geq 15 \mathrm{~d}$ per month for more than 3 months, which has the features of migraine headache $\geq 8 \mathrm{~d}$ per month. ${ }^{1}$ The burden of migraine is substantial, particularly in terms of disability, comorbidities, and impact on the health care system. In Canada, migraine is the sixth leading cause of disability-adjusted life years. ${ }^{2}$ A number of comorbidities have been found to be more common among individuals with migraine compared to the general population, and higher rates of comorbid conditions appear to occur among individuals with CM relative to those with EM. ${ }^{3-9}$ Migraine also imposes high health care costs, including medications as well as health care provider visits, procedures, and hospitalizations and emergency department visits. ${ }^{10}$

In 2010 to 2011, an estimated $8.3 \%$ of Canadians reported having been diagnosed with migraine, of which females reported having migraine more than twice as often as males. ${ }^{11}$ Among surveyed Canadians living with migraine, the International Burden of Migraine Study (IBMS) found that $92 \%$ and $8 \%$ were considered to have EM and CM, respectively, in 2009. ${ }^{12}$ These estimates may not be representative of the actual burden of migraine, as many individuals with migraine either do not seek medical care for their condition or are not properly diagnosed. ${ }^{6,13-16}$ For example, it has been reported that only $20 \%$ to $25 \%$ of individuals with CM receive an accurate diagnosis. ${ }^{14,15}$ Recently, Pavlovic et al. (2019) developed and validated a claims-based algorithm in the United States to identify individuals with undiagnosed $\mathrm{CM} .{ }^{17}$ Considering that Canadian administrative health data does not contain a diagnostic code for $\mathrm{CM}$, it may be possible that this algorithm could be used to identify individuals with $\mathrm{CM}$ at the population level in Canada.

Given the health burden and cost of migraine, information on the characteristics of individuals with migraine would be useful for anticipating needs in subgroups of patients, particularly $\mathrm{CM}$ and EM, and assisting policy makers in priority setting. Recently, Altura et al. (2019) developed a profile of individuals living with migraine in Canada using results from a cross-sectional community-based survey, which focused on health-related variables such as health status, quality of life, stigma, depression, and social support. ${ }^{18}$ Additional updated information describing the demographic and clinical characteristics, including pharmacological treatment, according to migraine type would be beneficial. The objectives of the present study were to: (1) apply a recently developed USA-based case definition to Canadian administrative health data for the identification of individuals with CM and (2) better understand the characteristics of individuals with EM and $\mathrm{CM}$, as identified by this algorithm. The current study describes the demographic and clinical characteristics, including the number and type of acute and preventative migraine medications used, among patients with EM and CM in Alberta.

\section{Materials ANd Methods}

This retrospective population-based cross-sectional study is reported according to STROBE guidelines. ${ }^{19}$ The institutional review board at the University of Alberta (Pro00083495) approved this study. This is a study of administrative data without any intervention. No study participants were placed at risk as a result of the study. Informed consent was not required.

\section{Data Source}

Administrative data from the Discharge Abstract Database (DAD), National Ambulatory Care Reporting System (NACRS), Practitioner Claims, and Pharmaceutical Information Network (PIN) were used. Data were linked to the Population Registry, which contains demographic information for all Albertans with Alberta Health Care Insurance Plan (AHCIP) coverage; the AHCIP is a publicly funded, government administered insurance plan that all Alberta residents are eligible for and over $99 \%$ participate. $^{20}$

DAD and NACRS include demographic, administrative, diagnostic, and procedural data on all patients discharged from hospital and facility-based ambulatory care clinics, respectively. The diagnostic data in these databases use International Classification of Disease - Version 10 - Canadian Enhancement (ICD-10-CA) codes, and contain a most responsible diagnosis field and up to 24 secondary diagnostic codes in the DAD and 9 secondary diagnostic codes in the NACRS. Practitioner Claims includes patient, provider, and service information on fee-for-service, alternative payment plan physician billing, and shadow billing. This database contains up to three ICD Version 9 - Clinical Modification (ICD-9-CM; Alberta specific) diagnostic codes per visit. PIN contains information on dispensed prescription medications from community pharmacies.

\section{Subject Selection}

Pavlovic et al. (2019) first selected a cohort of individuals with migraine according to the following criteria: $(1) \geq 18$ years of age on the CM screening date and (2) had $\geq 1$ migraine claim, no CM claim (does not exist within Canadian administrative health data), and no botulinum toxin injection procedure code related to migraine, within the 1 -year period before the CM screening date. ${ }^{17}$ Considering that the Alberta Medical Association Health Service procedure code for the injection of botulinum toxin for the prophylaxis of $\mathrm{CM}$ (procedure code 13.590) applies to eligible patients 18 to 65 years of age and came into effect on April 1, 2014, in this study, a cohort of individuals was selected who were 19 to 65 years of age with at least one hospitalization or physician visit containing a recorded diagnosis of migraine (ICD-10-CA G43 or ICD-9-CM 346 located in any diagnostic field, respectively) between April 1, 2015 and March 31, 2017 (inclusion period); the date of the first hospitalization or physician visit containing a migraine diagnostic code during the inclusion period was considered to be the index date. Other eligibility criteria included: (1) having no 13.590 procedure code during the inclusion period or up to 2 years before and 1 year after the index date and (2) having continuous AHCIP coverage for at least 2 years before and 1 year after the index date.

The case definition from Pavlovic et al. (2019) used to identify $\mathrm{CM}$ among those with migraine was based on 4 predictors, which were assessed during the 1-year pre-index period in this study and included: $(1) \geq 24$ versus $<24$ health care visits of any type (i.e., hospitalizations, physician visits, ambulatory visits, and emergency department visits), (2) $\geq 15$ versus $<15$ pharmacy 


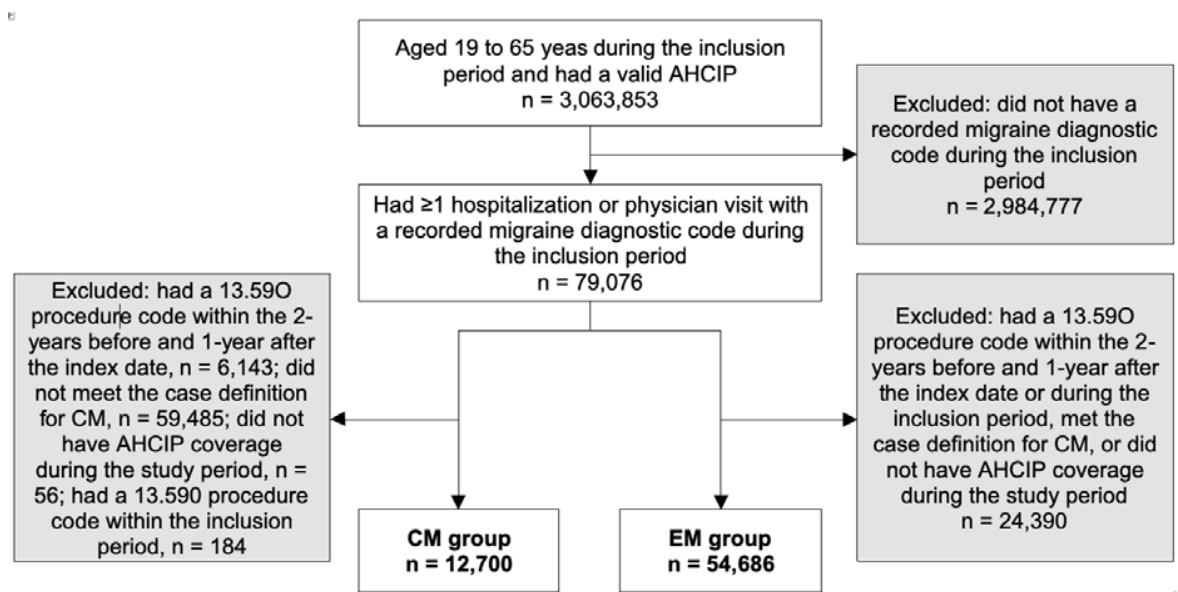

Figure 1: Flow diagram of subject selection. AHCIP: Alberta Health Care Insurance Plan; CM: chronic migraine; EM: episodic migraine.

prescription dispensations for acute migraine medications, including opioids, (3) 1 versus 0 or $\geq 2$ versus 0 pharmacy prescription dispensations for unique migraine preventive drug classes, and (4) female versus male. ${ }^{17}$ Detailed in Supplementary Table 1 , the acute and preventative migraine drugs used in this study were modified from Pavlovic et al. (2019) because pharmacotherapy treatment guidelines and medication availability differ between the United States and Canada. ${ }^{13,17,21,22}$ Acute migraine medications considered included antiemetics, ergots, nonsteroidal anti-inflammatory drugs (NSAIDs), triptans, and opioids; the preventative migraine medications considered were antidepressants, antiepileptics, antihistamines, antihypertensives, and calcium antagonists. A multivariable logistic regression model was used to determine the predicated probably of having CM. ${ }^{17}$ In their study, Pavlovic et al. (2019) found that a predicted probability of $\geq 0.55$ resulted in identifying undiagnosed $\mathrm{CM}$ with a sensitivity of $78.1 \%$ and specificity of $72.7 \%{ }^{17}$ Therefore, the same predicted probability threshold was applied in this study. Based on selection criteria, individuals with a predicated probability $\geq 0.55$ were considered to have $\mathrm{CM}$, but were not treated with botulinum toxin for the prophylaxis of migraine. Considering that a migraine diagnostic code is a highly specific indicator of migraine case status, ${ }^{23}$ individuals within the cohort were considered to have EM if they did not meet the criteria for CM.

\section{Study Measures}

Subject characteristics on the index date included age, sex, and urban or rural residence, which was determined by the second digit of the postal code. ${ }^{24}$ A Charlson Comorbidity Index score was determined during the 2-year pre-index period using ICD-10-CA and ICD-9-CM codes of 17 different specific medical conditions, which were weighted according to their potential for influencing mortality to calculate the score; average scores were presented, and categorized as $0,1,2$ or $\geq 3 .{ }^{25}$ Specific comorbidities of interest were also determined for allergic rhinitis, anxiety, asthma, cancer, cerebrovascular disease, chronic kidney disease, depression, diabetes mellitus, drug dependence, epilepsy and recurrent seizures, gastroesophageal reflux disease, headache (nonmigraine), heart failure, hyperlipidemia, hypertension, irritable bowel syndrome, ischemic heart disease, neck or back pain and fibromyalgia, opioid dependence, other mood disorders, pain, and sleep disturbances. An individual was considered to have a specific comorbidity if they had at least one hospitalization or physician visit with an associated diagnostic code for the comorbidity located in any diagnostic field, during the 2-year pre-index period. Acute and preventative prescription migraine medication dispensations were categorized by drug class, and reported over the 1-year post-index period.

\section{Statistical Analyses}

Descriptive statistics are reported as counts and percentages for categorical variables and means and standard deviations or 95\% confidence intervals (CI) for continuous variables. For group comparisons, statistical significance was assessed using a chi-squared test for categorical variables and a two-tailed independent t-test for continuous variables; point estimates and 95\% CI (lower and upper limits) are reported. A conventional alpha of 0.05 and two-tailed level of significance was used. Statistical analysis was performed using Python version 3.6.5.

\section{Results}

\section{Subject Selection}

Of the 3,063,853 Alberta residents with valid AHCIP coverage aged 19 to 65 years during the inclusion period, 79,076 received a recorded diagnostic code for migraine in any diagnostic field (Figure 1). After applying additional eligibility criteria, 12,700 individuals met the criteria for $\mathrm{CM}$ and the remaining 54,686 were considered to have EM.

\section{Characteristics}

Table 1 outlines the demographic and clinical characteristics of the CM and EM groups. The mean age of individuals with CM was slightly older than those who had EM (43 \pm SD 12 vs. $39 \pm$ SD 12 years of age; $95 \%$ CI 3-4). There were more females than males with EM (72.4\% females and $27.6 \%$ males), and significantly more females with CM compared with EM $(98.7 \%$ 


\section{Table 1: Demographic and clinical characteristics}

\begin{tabular}{|c|c|c|c|c|c|}
\hline Age overall & \multicolumn{2}{|c|}{ Chronic migraine } & \multicolumn{2}{|c|}{ Episodic migraine } & $\begin{array}{l}\text { Point estimate }[95 \% \\
\text { confidence intervals] }\end{array}$ \\
\hline Mean (SD) & 43 & (12) & 39 & (12) & $4[3,4]$ \\
\hline \multicolumn{6}{|l|}{ Age categories, $\%$ (count) } \\
\hline 19-24 years & $7.1 \%$ & $(908)$ & $12.7 \%$ & $(6972)$ & \\
\hline $25-29$ years & $9.5 \%$ & $(1210)$ & $12.5 \%$ & $(6861)$ & \\
\hline $30-34$ years & $11.8 \%$ & $(1503)$ & $14.0 \%$ & $(7632)$ & \\
\hline $35-39$ years & $12.7 \%$ & $(1617)$ & $13.6 \%$ & $(7443)$ & \\
\hline $40-44$ years & $12.7 \%$ & $(1615)$ & $13.1 \%$ & $(7160)$ & \\
\hline $45-49$ years & $12.6 \%$ & (1604) & $11.4 \%$ & $(6240)$ & \\
\hline $50-54$ years & $13.3 \%$ & $(1694)$ & $9.7 \%$ & $(5320)$ & \\
\hline $55-59$ years & $10.5 \%$ & $(1338)$ & $7.3 \%$ & $(4017)$ & \\
\hline $60-64$ years & $8.1 \%$ & $(1027)$ & $4.8 \%$ & $(2637)$ & \\
\hline$\geq 65$ years & $1.4 \%$ & (184) & $0.7 \%$ & $(404)$ & \\
\hline \multicolumn{6}{|l|}{ Sex, \% (count) } \\
\hline Female & $98.7 \%$ & (12536) & $72.4 \%$ & (39567) & $0.3[0.3,0.3]$ \\
\hline Male & $1.3 \%$ & (164) & $27.6 \%$ & $(15119)$ & \\
\hline \multicolumn{6}{|l|}{ Residence, \% (count) } \\
\hline Urban & $85.8 \%$ & $(10890)$ & $87.7 \%$ & $(47937)$ & $0.02[0.01,0.03]$ \\
\hline Rural & $14.2 \%$ & $(1802)$ & $12.3 \%$ & $(6705)$ & \\
\hline \multicolumn{6}{|l|}{$\begin{array}{l}\text { Charlson Comorbidity } \\
\text { Index }\end{array}$} \\
\hline Mean (SD) & 0.6 & $(1.1)$ & 0.2 & $(0.7)$ & $0.4[0.4,0.4]$ \\
\hline \multicolumn{6}{|l|}{ Categories, \% (count) } \\
\hline 0 & $63.0 \%$ & $(8000)$ & $83.5 \%$ & $(45686)$ & \\
\hline 1 & $24.6 \%$ & (3118) & $12.2 \%$ & $(6671)$ & \\
\hline 2 & $7.6 \%$ & (961) & $3.1 \%$ & $(1715)$ & \\
\hline$\geq 3$ & $4.9 \%$ & $(621)$ & $1.1 \%$ & $(614)$ & \\
\hline \multicolumn{6}{|l|}{ Comorbidities, \% (count) } \\
\hline Allergic rhinitis & $9.0 \%$ & $(1137)$ & $5.3 \%$ & $(2893)$ & $0.04[0.03,0.04]$ \\
\hline Anxiety & $34.9 \%$ & $(4428)$ & $16.2 \%$ & $(8868)$ & $0.2[0.2,0.2]$ \\
\hline Asthma & $18.7 \%$ & (2369) & $8.3 \%$ & $(4533)$ & $0.1[0.01,0.1]$ \\
\hline Cancer & $7.0 \%$ & $(888)$ & $3.4 \%$ & (1836) & $0.04[0.03,0.04]$ \\
\hline Cerebrovascular disease & $2.0 \%$ & $(253)$ & $0.7 \%$ & (391) & $0.01[0.01,0.02]$ \\
\hline Chronic kidney disease & $1.3 \%$ & (159) & $0.2 \%$ & (133) & $0.01[0.01,0.01]$ \\
\hline Depression & $45.0 \%$ & $(5714)$ & $19.4 \%$ & $(10630)$ & $0.3[0.2,0.3]$ \\
\hline Diabetes mellitus & $9.1 \%$ & (1156) & $3.5 \%$ & (1906) & $0.06[0.05,0.06]$ \\
\hline Drug dependence & $5.4 \%$ & $(682)$ & $1.2 \%$ & $(665)$ & $0.04[0.04,0.05]$ \\
\hline $\begin{array}{l}\text { Epilepsy and recurrent } \\
\text { seizures }\end{array}$ & $2.8 \%$ & $(361)$ & $1.2 \%$ & $(635)$ & $0.02[0.01,0.02]$ \\
\hline $\begin{array}{l}\text { Gastroesophageal reflux } \\
\text { disease }\end{array}$ & $1.1 \%$ & (138) & $0.2 \%$ & (97) & $0.009[0.007,0.011]$ \\
\hline Headache, nonmigraine & $29.5 \%$ & $(3752)$ & $16.8 \%$ & $(9171)$ & $0.1[0.1,0.1]$ \\
\hline
\end{tabular}


Table 1: (Continued)

\begin{tabular}{|c|c|c|c|c|c|}
\hline \multirow[b]{2}{*}{ Heart failure } & \multicolumn{2}{|c|}{ Chronic migraine } & \multicolumn{2}{|c|}{ Episodic migraine } & \multirow{2}{*}{$\begin{array}{c}\begin{array}{l}\text { Point estimate }[95 \% \\
\text { confidence intervals }]\end{array} \\
0.006[0.004,0.007]\end{array}$} \\
\hline & $0.8 \%$ & (99) & $0.2 \%$ & $(112)$ & \\
\hline Hyperlipidemia & $4.9 \%$ & (624) & $3.8 \%$ & (2069) & $0.01[0.01,0.02]$ \\
\hline Hypertension & $22.3 \%$ & $(2831)$ & $11.4 \%$ & $(6217)$ & $0.1[0.1,0.1]$ \\
\hline Irritable bowel syndrome & $3.8 \%$ & (487) & $1.5 \%$ & $(798)$ & $0.02[0.02,0.03]$ \\
\hline Ischemic heart disease & $4.5 \%$ & (566) & $1.8 \%$ & $(962)$ & $0.03[0.02,0.03]$ \\
\hline $\begin{array}{l}\text { Neck or back pain/ } \\
\text { fibromyalgia }\end{array}$ & $27.8 \%$ & (3533) & $12.2 \%$ & (6683) & $0.2[0.1,0.2]$ \\
\hline Opioid dependence & $0.4 \%$ & (49) & $0.03 \%$ & (16) & $0.004[0.002,0.005]$ \\
\hline Other mood disorders & $10.8 \%$ & (1375) & $2.5 \%$ & $(1386)$ & $0.08[0.08,0.09]$ \\
\hline Pain & $0.8 \%$ & (106) & $0.05 \%$ & (27) & $0.01[0.01,0.01]$ \\
\hline Sleep disturbances & $15.1 \%$ & $(1920)$ & $6.4 \%$ & (3497) & $0.09[0.08,0.09]$ \\
\hline
\end{tabular}

vs. $72.4 \%$, 95\% CI $0.3-0.3)$. Over $85 \%$ lived in urban areas (85.5\%: CM; 87.7\%: EM). The overall mean Charlson Comorbidity Index score was significantly greater in the CM group compared to the EM group $(0.6 \pm$ SD 1.1 vs. $0.2 \pm$ SD $0.7,95 \%$ CI 0.4-0.4; Table 1). The comorbidities most common ( $>10 \%$ of individuals) in both migraine groups were depression, anxiety, headache (nonmigraine), neck or back pain/fibromyalgia, and hypertension. Additionally, over $10 \%$ of individuals within the CM group also had asthma, sleep disturbances, and other mood disorders. A significantly larger proportion of individuals with CM displayed each of the specific comorbidities of interest compared with EM.

\section{Medication Use}

Acute and preventative migraine prescription medication dispensations that occurred during the 1-year post-index period are presented in Figures 2 and 3, respectively. Overall, $67 \%$ of migraineurs (80.6\%: CM; 63.4\% EM) were dispensed an acute migraine medication during the 1-year period. Among those with medication dispensations, individuals with CM had significantly more acute migraine medication dispensations overall compared with EM (13.6 \pm CI $13.0-14.2$ vs. $4.6 \pm$ CI $4.5-4.7,95 \%$ CI 8.6-9.4), which extended across all five drug classes (Figure 2; Supplementary Table 2). Among the different types of acute migraine medication drug classes, triptans, NSAIDs, and opioids were the most commonly used in both migraine groups. More than twice as many individuals with $\mathrm{CM}$ received a dispensation for an opioid compared with EM (53.1\%: CM, 25.7\%: EM; $95 \%$ CI 0.3-0.3).

During the 1-year observation period, $58.0 \%$ and $28.9 \%$ of individuals with CM and EM, respectively, received a preventative migraine drug dispensation (Figure 3; Supplementary Table 3). Among individuals who received a preventative migraine dispensation, those with CM received an average of 12.6 ( \pm CI 11.6-13.6) dispensations during the year, which was significantly more than those with EM (5.0 \pm CI 4.8-5.2, 95\% CI 6.9-8.4). Antidepressant, antiepileptic, and antihypertensive medications were the most commonly dispensed preventative migraine drug classes in both groups, and individuals with $\mathrm{CM}$ received significantly more dispensations for these drug classes compared with EM.

\section{Discussion}

In this administrative health data population-based study, a case definition originally developed to identify individuals with undiagnosed CM in the United States, ${ }^{17}$ was applied to individuals with a diagnostic code for migraine in Alberta for the identification of $\mathrm{CM}$ and through exclusion, EM. Among the 59,485 individuals who met eligibility criteria, $19 \%$ were considered to have CM and the remaining $81 \%$ had EM. Although the proportion of individuals identified as having CM and EM were higher and lower, respectively, in this study compared to the survey-based IBMS, the profile of these migraineurs was similar between the studies. ${ }^{10,12}$ The demographic and clinical characteristics of individuals with CM and EM were also consistent with other previous epidemiologic and comorbidity findings $s^{4,6-9,11}$; prevalence of migraine was highest in middle age, the majority were female, the most common comorbidity was depression, and individuals with $\mathrm{CM}$ had higher proportions of comorbidities compared with EM. Comparable to others, ${ }^{26-28}$ we also found that more individuals with $\mathrm{CM}$ used acute and preventative migraine medications, and among those who used medications, individuals with CM had more dispensations than EM, which was found across nine of ten drug classes; opioid use was found to be common among both migraine groups. Collectively, it appears that this algorithm can be applied to routinely collected data in Canada for the identification of CM and EM at the populationlevel, as evidenced by the concordance between our findings and others who have used various approaches.

\section{Characteristics}

The average age and female preponderance were congruent with previous reports. ${ }^{4,11}$ While the vast majority of individuals with CM were female (98.7\%), this was likely due to the case definition applied, which included the predictor of female; a similar proportion of females were identified as having undiagnosed CM when this algorithm was applied in the USA. ${ }^{17}$ 

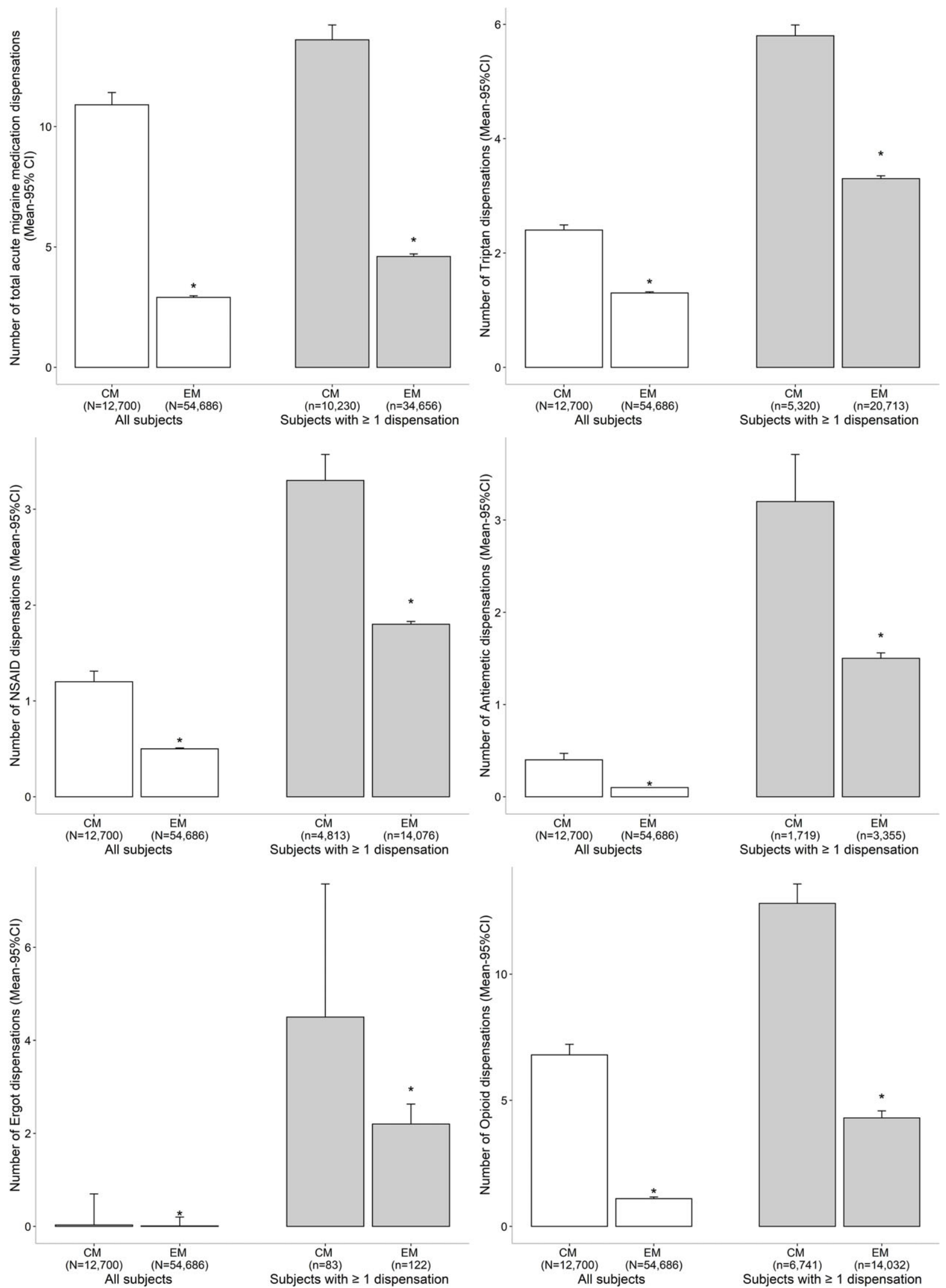

Figure 2: Acute migraine prescription medication dispensations during the 1-year post-index period. *Significant difference between the chronic migraine and episodic migraine groups as determined by a two-tailed independent $t$-test. CI: confidence interval; CM: chronic migraine; EM: episodic migraine; NSAID: non-steroidal anti-inflammatory drug. 

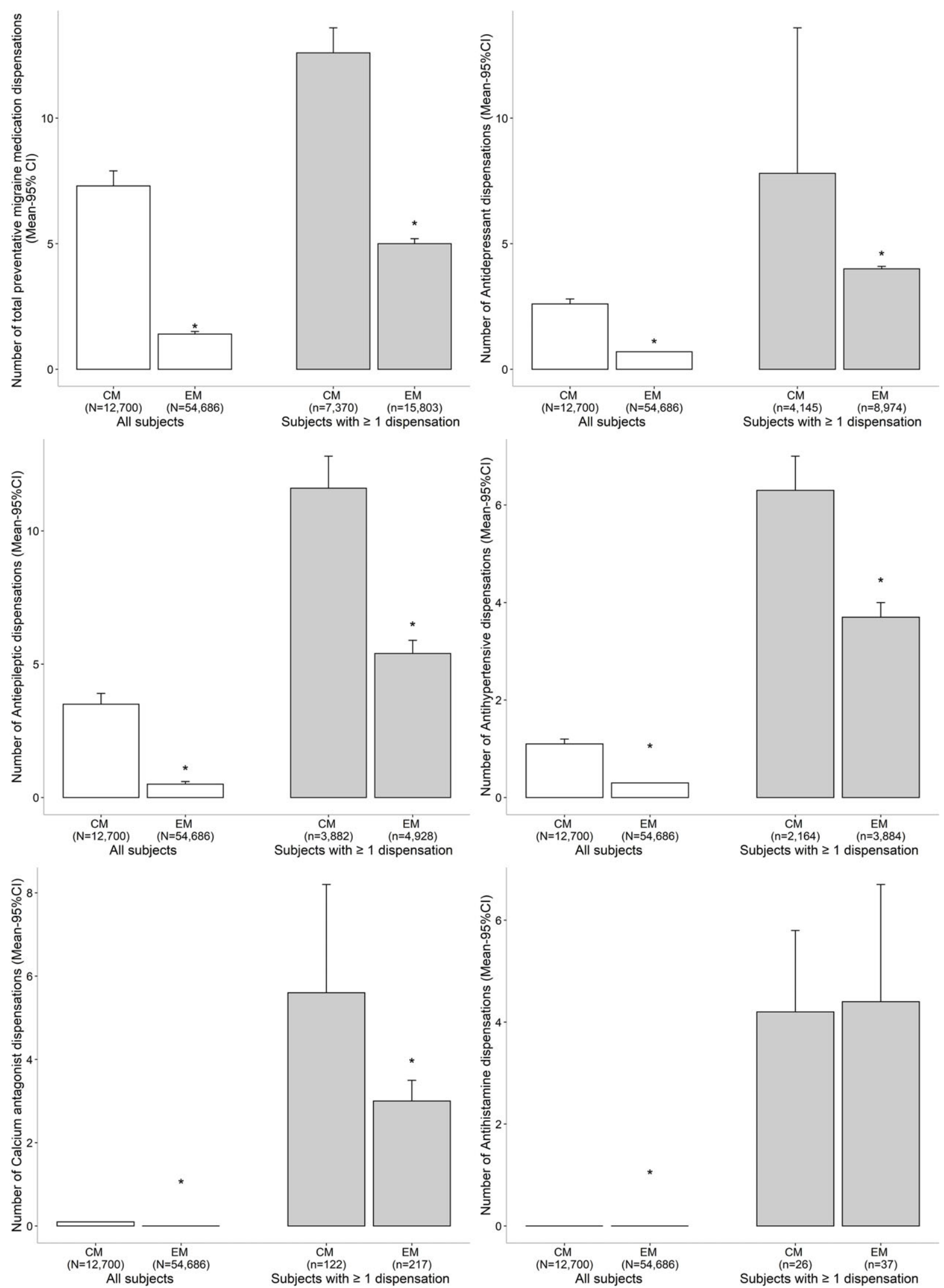

Figure 3: Preventative migraine prescription medication dispensations during the 1-year post-index period. *Significant difference between the chronic migraine and episodic migraine groups as determined by a two-tailed independent t-test. CI: confidence interval; CM: chronic migraine; EM: episodic migraine. 
A number of comorbidities have been found to be more common among individuals with migraine compared to the general population, and include neurologic, cardiovascular, non-headache pain, respiratory, and psychiatric conditions, of which depression and anxiety are most prevalent. $^{3-5}$ Additionally, previous studies have demonstrated higher rates of comorbid conditions among individuals with CM relative to those with EM. ${ }^{6-9}$ Using data from the American Migraine Prevalence and Prevention study, a longitudinal population-based survey, Buse et al. (2010) found that those with $\mathrm{CM}$ were approximately twice as likely to have depression, anxiety, chronic bronchitis, ulcers, and chronic pain compared to EM. ${ }^{7}$ Similarly, the most commonly observed comorbidities in this study occurred twice as often in those with CM compared with EM, and included psychiatric (i.e., depression, anxiety), neurologic (nonmigraine headache), pain (neck or back/ fibromyalgia), and cardiovascular (hypertension) conditions.

\section{Prescription Migraine Medication Use}

Comprehensive migraine therapy includes self-management of lifestyle factors and triggers, as well as pharmacotherapy. ${ }^{13}$ Canadian guidelines recommend ibuprofen, naproxen sodium, and acetaminophen as first-line acute migraine medications, and triptans and antiemetics as second-line; first-line preventative migraine medication recommendations include antidepressants and antihypertensives, and antiepileptics as second-line. ${ }^{13}$ Stokes et al. (2011) found that among Canadians with migraine who participated in the IBMS, over $70 \%$ reported having taken an acute migraine medication within the past four weeks, of which triptans and NSAIDs were the most commonly reported medications (antiemetics were not reported in that study); those with $\mathrm{CM}$ reported more days of medication use compared to those with $\mathrm{EM},{ }^{10}$ which is very similar to the results of our study. It has been reported that approximately $39 \%$ of individuals with migraine would benefit from preventative migraine therapy, ${ }^{29}$ and in the current study, $34 \%$ of migraineurs received a preventative migraine drug dispensation during the 1-year period. Antidepressants were the most commonly dispensed preventative migraine medication among individuals with CM and EM, which is in alignment with others, ${ }^{10}$ and may be partially driven by the comorbid profile of migraineurs. It has been noted that while opioids may be helpful in certain individuals with migraine, their use is considered controversial and it is suggested that they not be used routinely. ${ }^{30,31}$ However, opioid use was found to be common among both migraine groups. Similar levels of opioid use among individuals with migraine have also been observed recently in other large population-level studies. ${ }^{26-28}$ These findings are concerning given that frequent use of opioids increases the propensity of developing medication-overuse headache and/or the progression of EM to CM. ${ }^{32}$ Opioids may also make individuals more refractory to other acute migraine medications, including triptans. ${ }^{33}$ In some cases, opioid use can also lead to misuse or abuse, and result in dependence. Buse et al. (2012) found that among individuals with migraine who were currently using opioids, $17 \%$ met the criteria for probable dependence. ${ }^{34}$ The underlying determinants of opioid use among migraineurs is reported to be multifactorial and may include factors such as efficacy, cost, tolerability, and side effects of current oral acute and preventative migraine medications, as well as disease-, physician-, and patient-driven factors..$^{28,35,36} \mathrm{~A}$ deeper understanding of the root causes driving opioid use is needed in order to prevent the negative consequences of this common pattern of treatment.

\section{Limitations}

This study has several important strengths, including the large size, population-based design, and the use of a recently developed algorithm to identify individuals with CM. However, this study is also subject to a number of limitations that should be taken into consideration when interpreting results. Retrospective administrative claims-based studies use administrative data as opposed to medical records, and therefore there is a potential for misclassification of the study groups or measures. With that said, using migraine diagnostic codes from administrative claims data has been shown to reliably detect migraine status, but this strategy has also been shown to miss a large number of individuals with migraine in the population, ${ }^{23}$ as many individuals with migraine either do not seek medical care for their condition or are not properly diagnosed. ${ }^{6,13-16}$ O'Brien et al. (1994) found that only $46 \%$ of 500 surveyed Canadians who met the International Headache Society criteria for migraine reported being diagnosed by a physician. ${ }^{16}$ Individuals included in this study are those who received a diagnostic code for migraine by a physician, and therefore may represent less than half of migraineurs in Alberta.

The case definition used to identify individuals with CM in the current study was adapted from Pavlovic et al. (2019) because pharmacotherapy treatment guidelines and medication availability differ between the USA and Canada. ${ }^{13,17,21,22}$ Additionally, this algorithm was developed to identify adults with undiagnosed $\mathrm{CM}$, and therefore excludes individuals who have received botulinum toxin for the treatment of CM, and selects those with higher previous health care resource utilization and medication use, as well as primarily females. ${ }^{17}$ Considering that in the current study individuals with $\mathrm{CM}$ were excluded if treated with botulinum toxin (reflecting $8 \%$ of the 79,076 adults between the ages of 19 and 65 years who received a recorded diagnostic code for migraine), in order to replicate the claims-based algorithm by Pavlovic et al. (2019), ${ }^{17}$ and that Canadian administrative health data do not contain a diagnostic code for CM, individuals identified as having CM in the current study included those with undiagnosed $\mathrm{CM}$ and those with diagnosed $\mathrm{CM}$, but not treated with botulinum toxin. Individuals with migraine who were less than 19 and over 65 years of age, which represents approximately $10 \%$ and $5 \%$ of the respective age groups, ${ }^{11,16}$ could not be included in this study due to age restrictions of the botulinum toxin procedure code. Although reports show that up to 4 times as many females have CM compared with males, ${ }^{11,37}$ validation of the algorithm among males would increase its applicability, as outlined by Pavlovic et al. (2019). ${ }^{17}$ Collectively, the generalizability of our findings may be limited.

The PIN database only provides information on prescription medication dispensations from community pharmacies, and therefore may not represent actual medication uptake by individuals. Additionally, it is not known whether medications were being taken specifically for migraine or for other conditions such as arthritis, depression, hypertension or epilepsy. Use of over-the-counter medications, prescription medications provided 
in a hospital or secondary care setting, and other nonpharmacotherapy self-management techniques are not captured within provincial administrative data and therefore, not reported.

\section{Conclusions}

In this retrospective population-based cross-sectional study, a claims-based case definition was adapted for application within administrative health data in Alberta. Use of this algorithm identified individuals with CM and EM who displayed characteristics consistent with previous reports using other approaches, including higher rates of comorbid conditions among individuals with CM relative to those with EM. Pharmacologic therapy was found to be in concordance with recommended treatment, except for opioid use, which was much more common than recommended in both CM and EM. A consideration for future research may be to better understand the characteristics of migraineurs using opioids, as well as the health care setting in which they were prescribed, such that patient and prescriber education can be ideally targeted.

The algorithm used in the current study may be a useful and efficient means of identifying subtypes of migraine on a population-level using routinely collected health data in Canada. Findings from this study will be useful for researchers and clinicians, including utilizing this algorithm to investigate outcomes of interest in EM and CM compared to those without migraine, as well as the potential need for education and monitoring use of opioids among those with migraine, and in particular, those with CM.

\section{ACKNOWLedgments}

This study is based in part on data provided by Alberta Health and Alberta Health Services. The interpretation and conclusions contained herein are those of the researchers and do not necessarily represent the views of the Government of Alberta or Alberta Health Services. Neither the Government of Alberta/ Alberta Health nor Alberta Health Services express any opinion in relation to this study.

\section{Funding}

The Real World Evidence Unit at the University of Alberta received financial support from Allergan, Incorporated for this research. The sponsor had the right to comment on the manuscript prior to submission, but the final decision regarding content and final submission of the manuscript remained with LR and SK.

\section{CONFLict of InTEREST}

The authors(s) declared the following potential conflicts of interest with respect to the research, authorship, and/or publication of this article: LR, SK, KW, and KM are members of the Real World Evidence Unit, an academic entity at the University of Alberta that conducts research including investigator-initiated industry-funded studies. TR is an assistant professor at the University of Alberta, and received no research or direct funding for this study; they have received an advisory board honorarium from Teva Pharmaceuticals. WB received advisory board honoraria from Allergan, Lundbeck, Eli Lilly, and Aralez, and a speaker honorarium from Allergan. FA received speaker honoraria and/or payment for consulting from Teva Pharmaceuticals, Eli Lilly, Novartis, Allergan, Aralez, and Lundbeck.

\section{Statement of Authorship}

$\mathrm{LR}, \mathrm{KW}, \mathrm{KM}$, and SK contributed to the study concept and design, KW conducted the analysis, and KM prepared the initial manuscript draft. All authors contributed to interpretation of the data and critical revision of the manuscript for intellectual content. LR and SK provided study supervision.

\section{SuPPlementary Material}

To view supplementary material for this article, please visit https://doi.org/10.1017/cjn.2021.68.

\section{REFERENCES}

1. Headache Classification Committee of the International Headache Society (IHS) The International Classification of Headache Disorders, 3rd edition. Cephalalgia. 2018;38:1-211.

2. Global Burden of Disease Compare [online]. https://vizhub. healthdata.org/gbd-compare/

3. Saunders K, Merikangas K, Low NCP, Korff MV, Kessler RC. Impact of comorbidity on headache-related disability. Neurology. 2008;70:538-47.

4. Bigal ME, Lipton RB. The epidemiology, burden, and comorbidities of migraine. Neurologic Clinics. 2009;27:321-34.

5. Amoozegar F. Depression comorbidity in migraine. Int Rev Psychiatry. 2017;29:504-15.

6. Burch RC, Buse DC, Lipton RB. Migraine: epidemiology, burden, and comorbidity. Neurolog Clinics. 2019;37:631-49.

7. Buse DC, Manack A, Serrano D, Turkel C, Lipton RB. Sociodemographic and comorbidity profiles of chronic migraine and episodic migraine sufferers. J Neurol Neurosurg Psychiatry. 2010;81:428-32.

8. Buse DC, Silberstein SD, Manack AN, Papapetropoulos S, Lipton RB. Psychiatric comorbidities of episodic and chronic migraine. J Neurol. 2013;260:1960-9.

9. Manack AN, Buse DC, Lipton RB. Chronic migraine: epidemiology and disease burden. Curr Pain Headache Reports. 2011;15: 70-8.

10. Stokes M, Becker WJ, Lipton RB, et al. Cost of health care among patients with chronic and episodic migraine in Canada and the USA: results from the International Burden of Migraine Study (IBMS). Headache. 2011;51:1058-77.

11. Ramage-Morin PL, Gilmour H. Prevalence of migraine in the Canadian household population. Health Reports. 2014;25:10-6.

12. Blumenfeld AM, Varon SF, Wilcox TK, et al. Disability, HRQoL and resource use among chronic and episodic migraineurs: results from the International Burden of Migraine Study (IBMS). Cephalalgia. 2010;31:301-15.

13. Becker WJ, Findlay T, Moga C, Scott NA, Harstall C, Taenzer P. Guideline for primary care management of headache in adults. Can Family Phys. 2015;61:670-9.

14. Dodick DW, Loder EW, Manack Adams A, et al. Assessing barriers to chronic migraine consultation, diagnosis, and treatment: results from the Chronic Migraine Epidemiology and Outcomes (CaMEO) study. Headache. 2016;56:821-34.

15. Bigal ME, Serrano D, Reed M, Lipton RB. Chronic migraine in the population. Neurology. 2008;71:559-66.

16. O'Brien B, Goeree R, Streiner D. Prevalence of migraine headache in Canada: a population-based survey. Int J Epidemiol. 1994; 23:1020-6. 
17. Pavlovic JM, Yu JS, Silberstein SD, et al. Development of a claims-based algorithm to identify potentially undiagnosed chronic migraine patients. Cephalalgia. 2019;39:465-76.

18. Altura KC, Patten SB, Williams JVA, Fiest KM, Jetté N. Living with migraine in Canada - a national community-based study. Can J Neurolog Sci. 2019;46:216-23.

19. von Elm E, Altman DG, Egger M, et al. The Strengthening the Reporting of Observational Studies in Epidemiology (STROBE) statement: guidelines for reporting observational studies. Lancet. 2007;370:1453-7.

20. Jin Y, Elleho E, Sanderson M, Malo S, Haan M, Odynak D. Comparison of Alberta population counts between the AHCIP registry and the 2006 census. Edmonton: Health and Wellness; 2009.

21. Pringsheim T, Davenport W, Mackie G, et al. Canadian Headache Society guideline for migraine prophylaxis. Can J Neurolog Sci. 2012;39:S1-S59.

22. Worthington I, Pringsheim T, Gawel MJ, et al. Canadian Headache Society guideline: acute drug therapy for migraine headache. Can J Neurolog Sci. 2013;40:S1-S3.

23. Kolodner K, Lipton RB, Lafata JE, et al. Pharmacy and medical claims data identified migraine sufferers with high specificity but modest sensitivity. J Clin Epidemiol. 2004;57:962-72.

24. du Plessis V, Beshiri R, Bollman RD, Clemenson H. Definitions of Rural. Statistics Canada; 2001.

25. Charlson ME, Pompei P, Ales KL, MacKenzie CR. A new method of classifying prognostic comorbidity in longitudinal studies: development and validation. J Chronic Dis. 1987;40:373-83.

26. Bonafede M, Sapra S, Shah N, Tepper S, Cappell K, Desai P. Direct and indirect healthcare resource utilization and costs among migraine patients in the United States. Headache. 2018;58: 700-14.
27. Gilligan AM, Foster SA, Sainski-Nguyen A, Sedgley R, Smith D, Morrow P. Direct and indirect costs among United States commercially insured employees with migraine. J Occup Environ Med. 2018;60:1120-7.

28. Woolley JM, Bonafede MM, Maiese BA, Lenz RA. Migraine prophylaxis and acute treatment patterns among commercially insured patients in the United States. Headache. 2017;57:1399-408.

29. Lipton RB, Bigal ME, Diamond M, et al. Migraine prevalence, disease burden, and the need for preventive therapy. Neurology. 2007;68:343-9.

30. Becker WJ. Acute migraine treatment in adults. Headache. 2015; 55:778-93.

31. Levin M. Opioids in headache. Headache. 2014;54:12-21.

32. Bigal ME, Lipton RB. Excessive opioid use and the development of chronic migraine. Pain. 2009;142:179-82.

33. Ho TW, Rodgers A, Bigal ME. Impact of recent prior opioid use on rizatriptan efficacy. A post hoc pooled analysis. Headache. 2009; 49:395-403.

34. Buse DC, Pearlman SH, Reed ML, Serrano D, Ng-Mak DS, Lipton RB. Opioid use and dependence among persons with migraine: results of the AMPP study. Headache. 2012;52:18-36.

35. Hepp Z, Dodick DW, Varon SF, et al. Persistence and switching patterns of oral migraine prophylactic medications among patients with chronic migraine: a retrospective claims analysis. Cephalalgia. 2017;37:470-85.

36. Katić BJ, Krause SJ, Tepper SJ, Hu HX, Bigal ME. Adherence to acute migraine medication: what does it mean, why does it matter? Headache. 2010;50:117-29.

37. Adams AM, Serrano D, Buse DC, et al. The impact of chronic migraine: the Chronic Migraine Epidemiology and Outcomes (CaMEO) Study methods and baseline results. Cephalalgia. 2015;35:563-78. 